\section{A British Freshwater Nemertine}

ON July 12, 1944, while collecting planarians in the Cam at Cambridge, we found a small orangecoloured worm in the leaf axils of Glyceria aquatica stems. Afterwards many more were found. The general structure, including the proboscis, showed clearly that it was a nemertine. The only freshwater nemertine previously recorded from Great Britain was a single specimen found by Benham ${ }^{1}$ in the River Cherwell, of which, however, there is no full description. There is also a single record of a freshwater nemertine from Ireland in Co. Dublin ${ }^{2}$. The present record is therefore of interest.

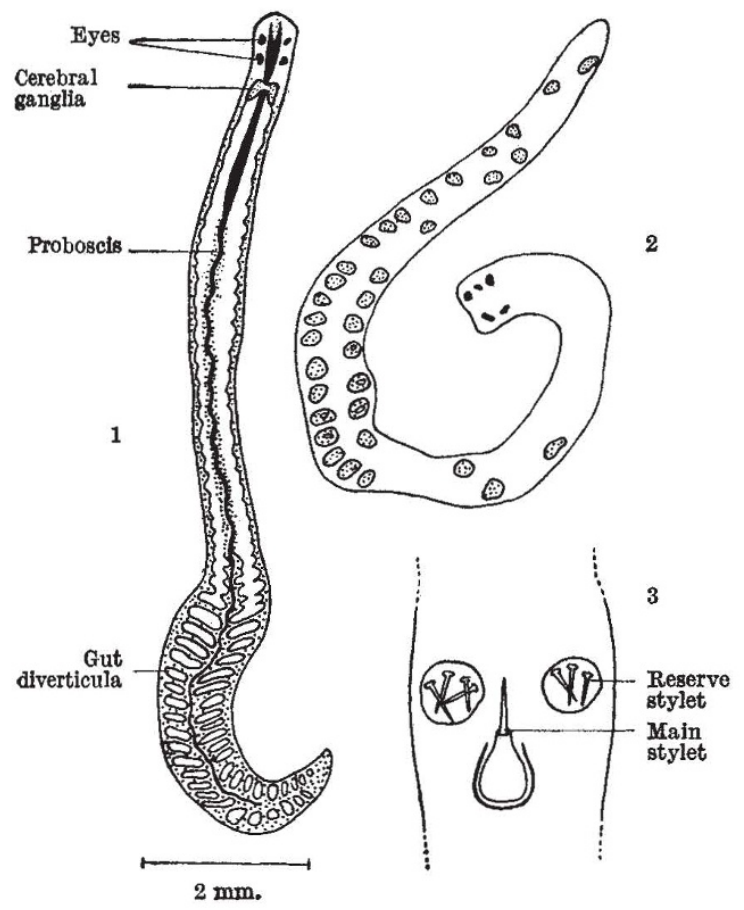

Prostoma Gracense: 1. Dorsal view. 2. Diagram showing distribution of ova. 3. Main and reserve stylets.

The worms were not uncommon in association with Glyceria, it being an easy matter to collect some six specimens in an hour. It was distributed widely in the Cam and its tributaries between Cambridge and Herston, although weirs occur along this stretch of the river. We did not have an opportunity to search beyond these limits, but we were informed that a single specimen had been found in the Great Ouse near Over (September 13, 1944). The worms were still abundant in the Cam throughout the autumn, but had disappeared by November 24, by which time the Glyceria with its associated turbellarian fauna was dying down. In July nearly all the individuals contained eggs, though none was found in specimens collected during November. Small isolated specimens have again been found this year, the first on March 21. It is of interest that one of these specimens contained actively moving sperm in the testes.

The worms ranged in size from $5 \mathrm{~mm}$. to $20 \mathrm{~mm}$. in length, and from $0.5 \mathrm{~mm}$. to $1 \mathrm{~mm}$. in width. They were usually orange-red in colour, but yellow and almost colourless individuals were found. In addition the surface was often flecked with brown pigment. The accompanying drawings indicate the general structure of the worms. The mouth and rhynchodæum have a common opening. There are four to eight eyes, the number and degree of development of which is very variable. The few specimens so far sectioned have ten proboscis nerves. There appear to be commonly two stylet sacs, each containing three to five reserve stylets, on either side of the main stylet. The length of the main stylet including the haft is approximately $95 \mu$.

Allowing for the variability in colour and eye number, the worms agree with the description of Prostoma (=Tetrastemma $=$ Stichostemma) grocense (Bohmig). This species is characterized by the possession of a common opening for the mouth and rhynchodæum (differentiating it from $P$. clep. sinoides), and by the possession of ten proboscis nerves (differentiating it from $P$. eilhardi). Bohmig records ${ }^{3} P$. groecense from the Botanic Gardens at Graz, and from mud in a stream at Prague. The nemertine recorded by Southern in Ireland was referred by him to the species $P$. clepsinoides. As Hallez points out ${ }^{4}$, the two species are closely related. Unfortunately, Benham's single specimen from Oxford was accidentally destroyed before it could be fully identified.

We should be glad to receive any information about the distribution of this freshwater nemertine in other parts of the British Isles.

We wish to thank Dr. C. F. A. Pantin for his interest and help in making these observations.

Rachel R. BratthwaIte.

Department of Zoology, Evely B. Clayton.

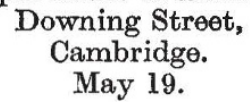

1 Benham, W. B., Nature, 46, 611 (1892).

Southern, R., Nature, 79, 8 (1908)

- Bohmig, L., Biol. Centrabl., 30, 561 (1910).

- Hallez, P., Bull. Soc. Zool. France, 35, 62 (1910).

\section{The Popliteal Facet in Men who Habitually Squat}

Some interest has centred around the variations in the lower end of the femur occasioned by the squatting posture ${ }^{1-4}$, and the present communication is to record yet another variation in the lower end of femora from Punjabis of lower classes, who adopt the squatting posture not only during work but also during rest. In a series of two hundred femora examined, a curved facet, covered with cartilage, was detected in all of them in the posterior part of the lateral aspect of the lateral condyle. It was well marked in some, less so in others, but was present in all. This facet may be looked upon as an extension of the femoral condylar articular cartilage on the lateral aspect posteriorly, just as the quadriceps facet ${ }^{1}$ is an extension of cartilage anteriorly.

The popliteal muscle arising from the anterior end of the popliteal groove on the lateral side of the lateral femoral condyle, and being inserted on the upper end of the posterior surface of the tibia, lies in the popliteal groove during flexion of the knee joint but moves in an arc on the lateral side on the lateral femoral condyle during the movement of extension, until the tendon lies obliquely from before 